\title{
INSTITUTO MUNICIPAL DE ENSINO SUPERIOR DE PRESIDENTE PRUDENTE: ESTRUTURA FÍSICA E CURRICULAR DA EDUCAÇÃO FÍSICA DE UMA AUTARQUIA (1971-1988)
}

Jaqueline Costa Castilho Moreira

Universidade Estadual Paulista - UNESP, Faculdade de Ciências e Tecnologia, Departamento de Educação Física, Presidente Prudente, SP. E-mail: jackycastilho@fct.unesp.br.

\section{RESUMO}

O objetivo deste trabalho foi desvelar a história de uma autarquia da década de 1970 denominada de Instituto Municipal de Ensino Superior de Presidente Prudente (IMESPP), na perspectiva de entender como as estruturas físicas e o currículo revelam discursos velados dentro da História da Educação. Trata-se de uma investigação qualitativa, com enfoque na pesquisa documental, realizada a partir de fontes existentes em arquivos de domínio público sobre a instituição. Os resultados apontam uma recorrência de fenômenos típicos da configuração da Educação Física no ensino superior, em termos de semelhança de estruturação curricular ao modelo da Universidade de São Paulo (USP) e as vicissitudes de sua implantação em termos de infraestrutura. Acredita-se que este artigo tenha oferecido alguns conhecimentos sobre o IMESPP, que é mencionado em publicações sobre a história da Universidade Estadual Paulista "Júlio de Mesquita Filho" (UNESP), mas sem detalhamento.

Palavras-chave: Escola Municipal Superior de Educação Física, pesquisa documental, infraestrutura, currículo escrito, currículo real.

\section{PRESIDENTE PRUDENTE'S MUNICIPAL INSTITUTE OF HIGHER EDUCATION: PHYSICAL AND CURRICULAR STRUCTURE OF THE PHYSICAL EDUCATION OF AN AUTONOMOUS (1971-1988)}

\begin{abstract}
The objective of this work was to unveil the history of an autarchy of the 1970s called the Municipal Institute of Higher Education of Presidente Prudente (IMESPP), in order to understand how the physical structures and the curriculum reveal veiled discourses within the History of Education. This is a qualitative research, focusing on documentary research, carried out from sources in public domain archives about the institution. The results point to a recurrence of phenomena typical of the configuration of Physical Education in higher education, in terms of similar curricular structuring to the University of São Paulo (USP) model and the vicissitudes of its implementation in terms of infrastructure. It is believed that this article has offered some knowledge about the institution of IMESPP, which is mentioned in publications on the history of The Universidade Estadual Paulista "Júlio de Mesquita Filho" (UNESP), but without detail.

Keywords: Higher Municipal School of Physical Education, documentary research, infrastructure, written curriculum, real curriculum.
\end{abstract}




\section{INTRODUÇÃO}

Entre 1950 e 1960, a Educação Física e os desportos foram temáticas de destaque mundial, tendência disseminada também no Brasil, por meio de um movimento de cientifização do conhecimento sobre esporte e saúde proporcionado pela modernização e avanço do ensino superior da área. Também foi evidenciada nos acordos MEC-USAID (convênios de cooperação e de apoio técnico entre o Ministério da Educação e a Agency for International Development dos Estados Unidos) e nas políticas educacionais de expansão do ensino secundário, que resultaram na reforma de primeiro e segundo graus promulgada pela Lei $n^{\circ} 5.692$ de 1971.

O norteamento de ampliação do acesso ao ensino secundário, acrescido à obrigatoriedade da Educação Física em todos os níveis educacionais pelo Decreto-Lei $n^{\circ}$ 464/1969, amplificou a demanda por professores com formação na área. Neste momento histórico opinavam também sobre os desdobramentos da Educação Física escolarizada, o Conselho Federal de Educação e seu correspondente estadual (CEE) e o Departamento de Educação Física e Desportos (DED), a antiga Divisão de Educação Física (DEF) e seus departamentos correspondentes nos estados (neste caso o Departamento de Educação Física e Esportes paulista/DEFE). Sendo o primeiro, um conselho técnico para examinar e opinar sobre as ações relativas à implantação das políticas públicas educacionais; e a divisão e os departamentos referentes à Educação Física, órgãos públicos responsáveis pela fiscalização das instalações e profissionais dos esportes e da disciplina em âmbito escolar (MOREIRA, 2013).

Para dar conta do mercado receptivo para a profissão docente, foram estabelecidas políticas e ações educacionais visando incentivar a oferta de ensino superior. Vigorava ao final da década de 1960, a Lei no 5.540 (BRASIL, 1968) que fixava normas de organização e funcionamento do ensino superior e sua articulação com a escola média. Nesta prescrição, as universidades deveriam organizar ou reunir estabelecimentos com cursos já reconhecidos; ou ainda incorporar ou congregar estabelecimentos isolados de nível superior, da mesma localidade ou próximas.

O presente artigo abordará esta transição, tendo como objeto de estudo, o primeiro curso superior em Educação Física de Presidente Prudente, idealizado pelo professor Jurandir Paccini. A graduação foi autorizada pelo general Emílio Garrastazu Médici, presidente do período da ditadura militar (1969 -1974), a ser ministrada pela Escola Municipal Superior de Educação Física em 1971. Essa liberação fez parte do processo de criação de escolas superiores da área, sendo que a maioria delas, abertas em cidades paulistas (MOREIRA, 2013).

O Decreto no 68.777 (BRASIL, 1971) caracterizou a Escola Superior como uma autarquia municipal. O termo autarquia é definido no artigo 50 do Decreto-lei no 200 (BRASIL, 1967) como: "o serviço autônomo, criado por lei, com personalidade jurídica e patrimônio e receita próprios, para executar atividades típicas da Administração Pública, que requeiram, para seu melhor funcionamento, gestão administrativa e financeira descentralizada".

Sucintamente, as autarquias são integrantes da administração indireta, criadas e extintas por lei específica. Seus bens são públicos, não sendo suscetíveis a usucapião, penhora, alienação ou oneração; o pagamento de débitos judiciais ocorre por meio de precatórios; sua contabilidade é pública; a prescrição de ações contra as autarquias é quinquenal; recebem imunidade tributária e privilégio processual, sendo que se permite à autarquia, tratamento igual ao da fazenda pública, ou seja, prazo em dobro para recorrer e em quádruplo para contestar. Staford et al. (2008, p. 03) sugerem a autarquia como pessoa administrativa, "instituída pelo estado para o desempenho de atividade predeterminada, dotada, de características especiais"; com funções a serem executadas de forma descentralizada, sendo que nesta perspectiva as autarquias são auto administradas.

O entendimento dessa terminologia colabora na categorização dos documentos oficiais recuperados sobre a criação em 1971 da Escola Superior Municipal de Educação Física. Neste trajeto de constituição de um ensino superior na área da Saúde, houve percalços. Dentre eles, o desequilíbrio financeiro da autarquia, que resultou em sua falência, situação não abordada neste 
texto. O restante do levantamento conduz ao processo da extinção não de uma escola, mas do Instituto Municipal de Ensino Superior de Presidente Prudente (IMESPP), pela Lei Municipal n.으 2.625 (PRESIDENTE PRUDENTE, 1988). Houve a doação do patrimônio/bens, assim como os cursos foram integrados a UNESP, e as dívidas foram assumidas pelo ente criador, o Município de Presidente Prudente, em 1988 (LEITE, 1972; LIMA; RIBEIRO, 2013; OLIVEIRA, 2014).

O objetivo deste trabalho foi desvelar a história dessa autarquia municipal, na perspectiva de entender como as estruturas físicas e o currículo revelam discursos velados dentro da História da Educação.

\section{METODOLOGIA}

Considerando o objetivo do trabalho, optou-se por uma investigação de abordagem qualitativa, com enfoque na pesquisa documental, realizada a partir de fontes existentes em arquivos de domínio público e que se encontram disponibilizados online.

A pesquisa documental para Severino $(2007$, p.122) é uma fonte de:

[...] documentos no sentido amplo, ou seja, não só de documentos impressos, mas, sobretudo de outros tipos de documentos, tais como jornais, fotos, filmes, gravações, documentos legais. Nestes casos, os conteúdos dos textos ainda não tiveram nenhum tratamento analítico, são ainda matéria-prima, a partir da qual o pesquisador vai desenvolver sua investigação e análise.

Nessa investigação foram utilizados: decretos, legislações, pareceres do CEE entre outras normas publicadas em Diário Oficial, no "esporte.gov", no Portal do Senado, no Portal da Prefeitura de Presidente Prudente, em conteúdo digital da Universidade Estadual Paulista na página da Faculdade de Ciências e Tecnologia/FCT e do Laboratório de Informática Aplicada a Gestão Educacional/IAGE/Faculdade de Ciências e Letras de Araraquara/FCLAR.

O foco de uma análise documental não é somente considerar o conteúdo do registro, mas seu contexto, sua função e finalidade, sua autoria, sua autenticidade, credibilidade, representatividade e significação. Além dos aspectos relativos à fonte, é relevante explicitar o referencial teórico foram cotejadas obras de: Da Costa (1971), Leite (1972), Goodson (1995), Gnecco (2005), Escolano (2011), Lima e Ribeiro (2013), Moreira (2013) e Oliveira(2014). A interpretação dos dados buscou encontrar subsídios no conjunto de fontes e referencial teórico para que as contribuições deste estudo possam ter satisfatória relação com eventos relativos ao ensino superior dentro da periodização selecionada (1971-1988).

\section{RESULTADOS}

Por uma questão didática, os resultados foram elencados em patrimônio físico e currículo oficial. Faz parte do patrimônio físico da Escola Municipal de Educação Física, o prédio sede que ocupa a área onde está localizado o Departamento de Educação Física e o de Fisioterapia da FCT/UNESP da atualidade. A edificação de tijolinhos do final da década de 1960 é a mesma, porém com algumas adaptações e pequenas reformas. Na parte interna do bloco, as salas de aula ficavam com suas portas voltadas para o corredor, o que ocasionava um ruído muito grande. Não havia sala de professores. Apenas a administração que ocupava duas das salas do bloco, a sala da biblioteca com 571 obras e a sala de anatomia com um laboratório ocupando também dois espaços. No início do curso, os graduandos faziam as aulas práticas no Estádio Municipal de Esportes, construído em 1968 e no Ginásio Municipal de Esporte, este último localizado no Jardim Aviação. As aulas eram realizadas embaixo das arquibancadas. Ao Final da década de 1970 e meados de 1980 foi construído o ginásio coberto, existente na atualidade, com quadra 
poliesportiva e material para ginástica. O espaço e os equipamentos ficavam sobre a responsabilidade da Autarquia Municipal de Esportes de Presidente Prudente (AMEPP), tanto assim que é possível verificar ainda no presente equipamentos patrimoniados com a sigla AMEPP. Embora na grade curricular do curso existisse a disciplina de natação, não havia piscina. Esta somente foi construída no final da década de 1980, antes da integração do instituto a UNESP. Ainda perscrutando a infraestrutura oferecida para as práticas havia uma quadra poliesportiva externa sem cobertura cuja obra ficou pronta em outubro de 1982 e um alambrado coberto que abrigava os equipamentos de musculação, localizado no pátio, entre o prédio da Escola Superior e as mangueiras. Quanto à cantina, ela não existia. Foi encontrado o Decreto Municipal no 4.341 (PRESIDENTE PRUDENTE, 1981) que menciona que o espaço do atletismo era denominado de Ginásio de Atletismo "Paulo Egydio Martins", também de responsabilidade da Autarquia Municipal de Esportes de Presidente Prudente (AMEPP). Embora o espaço, a pista e equipamentos pudessem ser requeridos a qualquer tempo pela prefeitura, seu uso era priorizado para o curso de Educação Física.

Os conteúdos do curso obedeciam um currículo oficial baseado no modelo da Escola Superior de Educação Física de São Paulo (ESEFSP) ou Instituto de Educação Física da USP, como posteriormente foi nomeado. A graduação da Escola Municipal de Presidente Prudente tinha duração de três anos, "correspondendo a um total de 2.265 h/aula, incluindo a carga de 195 h/aula ministradas no último período letivo para a formação do Técnico Esportivo"(SÃO PAULO, 1973, p.02), graduando uma turma a cada seis meses. Em 1974, momento da primeira formatura do curso, a graduação em Educação Física foi reconhecida pelo Decreto no 74.015 (BRASIL, 1974), assinado por Ernesto Geisel, general do exército, presidente do Brasil entre 1974-1979. A década de 1980 foi importante para a Escola Superior de Educação Física. Neste corrente além de tornarse Instituto Municipal de Ensino Superior de Presidente Prudente (IMESPP) pela Lei $n^{\circ} 2.120$ (PRESIDENTE PRUDENTE, 1980), assinada pelo prefeito Paulo Constantino; houve a liberação de funcionamento para mais um curso, a graduação em Fisioterapia pelo Decreto no 84.507 (BRASIL, 1980), por João Baptista Figueiredo (1979-1985), último general presidente da ditadura militar. Como dividiam as mesmas instalações, o curso de Fisioterapia era diurno e o de Educação Física passou a ser oferecido no período noturno; o que reforça o caráter anteriormente indicado nos estudos de Gnecco (2005) sobre os cursos de três anos em Educação Física serem voltados à profissionalização. Reconhecido pelo MEC dois anos depois, por meio da Portaria Ministerial no 13, em 10 de janeiro de 1983, o curso em Fisioterapia tinha uma representação social diferenciada em relação à Educação Física, como aponta Oliveira (2014). A partir de junho de 1988 ocorreu a encampação do IMESPP pela Faculdade de Ciências e Tecnologia da UNESP - Campus de Presidente Prudente, através da Portaria Ministerial no 59 (SÃO PAULO, 2002), incorporação já prevista pela Lei no 5.540 (BRASIL, 1968).

\section{DISCUSSÃO}

As transformações decorrentes das políticas educacionais de expansão da década de 1960 condicionaram em muitas das instituições como ocorreria efetivamente o oferecimento do ensino superior. Para forjar reflexões sobre as vicissitudes enfrentadas pelas graduações, a compreensão sobre as estruturas físicas (ESCOLANO, 2011) e sobre os "currículos escritos" ou planejados e os "currículos ativos", aqueles que efetivamente tornam-se realidade (GOODSON, 1995) são conhecimentos necessários. Em termos de estruturas físicas, o prédio que sediava o curso de Educação Física na década de 1970, passou a atender também o curso de Fisioterapia na década de 1980, revezando-se em turnos. Como em outros estabelecimentos educacionais da década de 1970, as aulas de algumas das disciplinas do curso de Educação Física eram realizadas em espaços improvisados ou em instalações particulares; por exemplo, pela inexistência de piscina na graduação, as aulas de natação aconteciam ora em uma academia locada para tal uso ora no Clube 
Recreativo Ipanema (SÃO PAULO, 1973). Essa ausência de espaço próprio é recorrente em vários ambientes educacionais de ensino básico e superior, conforme relatos no Diagnóstico de Educação Física/Desportos no Brasil de Lamartine Da Costa (1971). Na obra, clubes, escolas e faculdades negociavam instalações esportivas subaproveitadas, sendo essa ação uma solução paliativa para o cumprimento da obrigatoriedade da Educação Física e da expansão do ensino sem planejamento adequado. Em outra perspectiva, autores como Escolano (2011) questionam o significado que os espaços disciplinares ocupam dentro de um ambiente educacional. $O$ excessivo aproveitamento do espaço em turnos, as perdas de território e a realização das atividades em espaços improvisados ou locados e fora do contexto do ambiente de ensino formal (básico ou superior) extrapolam finalidades ou funções, ao revelarem enfrentamentos hierárquicos, disputas entre campos, confronto de valores, entre outras representações e simbologias.

Ao compararmos os conteúdos oferecidos pelo IMESPP aos do Curso Superior de Educação Física da USP, considerado modelar; percebe-se algumas similaridades entre as graduações. Cotejando as disciplinas oferecidas pela Educação Física da USP (GNECCO, 2005) com as da Educação Física Municipal de Presidente Prudente na década de 1970, observa-se que as práticas esportivas assemelham-se. As disciplinas de metabologia, fisioterapia e traumatologia não aparecem na grade do IMESPP, o que torna seu currículo, nesse quesito, menos denso. Embora haja registro na documentação municipal que o curso de Educação Física era uma Licenciatura, e foram localizadas algumas disciplinas que atendiam essa área, no geral as disciplinas do "currículo real" do IMESPP eram mais voltadas às práticas esportivas, do que aos conteúdos de formação docente. Novamente o estudo de Gnecco (2005) sobre o curso de Educação Física na USP, clarifica a opção por esta tendência esportiva da instituição prudentina, já que, como outras instituições superiores, acompanhava o modelo de estruturação curricular da instituição paulistana. Essa informação corrobora não somente os registros levantados sobre a duração de três anos do curso do IMESPP, mas também a perspectiva que o curso estaria mais voltado à profissionalização na área, o que afina com seu oferecimento em período noturno, possibilitando aos graduandos da Educação Física que trabalhassem no período diurno e estudassem a noite.

\section{CONCLUSÃO}

Acredita-se que este artigo tenha oferecido alguns conhecimentos sobre a instituição do IMESPP, que é mencionada em publicações sobre a história da UNESP, mas sem detalhamento. A lógica social na construção e uso dos prédios que compunham o IMESPP, a organização do espaço, a explicitação das funções e atividades que ocorreram e aquelas que não aconteceram em suas estruturas físicas, acrescidos ainda às contradições entre o currículo prescrito e o real, comunicam em linguagem silenciosa como os espaços são distribuídos e ocupados, ou ainda as representações forjadas sobre a Educação Física e os Esportes e sobre aqueles, por eles talhados. Enfim um discurso permeado ainda por estigmatizações.

\section{REFERÊNCIAS}

BRASIL. Decreto-lei no 200, de 25 de fevereiro de 1967. Dispõe sobre a organização da Administração Federal, estabelece diretrizes para a Reforma Administrativa e dá outras providências. Disponível em: < http://www.planalto.gov.br/ccivil 03/decreto-lei/Del0200.htm >. Acesso em: 08 ago. 2017.

BRASIL. Lei no 5.540, de 28 de novembro de 1968. Fixa normas de organização e funcionamento do ensino superior e sua articulação com a escola média, e dá outras providências. Disponível em:< http://www.planalto.gov.br/ccivil 03/leis/l5540.htm>. Acesso em: 08 ago. 2017. BRASIL. Decreto no 68.777, de 21 de Junho de 1971. Autorização para o funcionamento da Escola Superior de Educação Física de Presidente Prudente - Autarquia Municipal, com sede em 
Presidente Prudente, SP. Disponível em:< http://www2.camara.leg.br/legin/fed/decret/19701979/decreto-68777-21-junho-1971-410546-publicacaooriginal-1-pe.html>. Acesso em: 08 ago. 2017.

BRASIL. Decreto no 74.015, de 7 de maio de 1974. Concede reconhecimento ao curso de Graduação em Educação Física da Escola Municipal de Educação Física de Presidente Prudente, Estado de São Paulo. Disponível em: < http://legis.senado.gov.br/legislacao/ListaPublicacoes.action?id=203446>. Acesso em: 08 ago. 2017.

BRASIL. Decreto no 84.507, de 25 de fevereiro de 1980, Autoriza o funcionamento do curso de Fisioterapia da Escola Municipal Superior de Educação Física de Presidente Prudente, São Paulo. Disponível em:< http://www2.esporte.gov.br/cedime/legislacao/leisEF/1980 NormasJuridicas(Textolntegral) DEC 0845072502 1980.jsp>. Acesso em: 08 ago. 2017.

Da COSTA, L. P. Diagnóstico de Educação Física e Desportos no Brasil. Brasília: CDRH-MP/DEF-MEC, 1971. $392 \mathrm{p}$.

ESCOLANO, A. A arquitetura como programa. Espaço-escola e currículo. In: FRAGO, A. V.;

ESCOLANO, A. Currículo, espaço e subjetividade: a arquitetura como programa. Tradução A. Veiga Neto. Rio de Janeiro: DP\&A, 2011. p. 19-58.

GNECCO, J.R. Reforma Universitária e a USP: a integração da Escola de Educação Física em 1969. 2005. 1 v. 294 f. Tese (Doutorado em Educação) - Faculdade de Educação, Universidade de São Paulo, São Paulo, 2005.

GOODSON, I. F. Currículo: teoria e história. Petrópolis,Vozes,1995. 140 p.

LEITE, J.F. A Alta Sorocabana e o espaço polarizado de Presidente Prudente. Presidente Prudente: FFCL de Presidente Prudente, 1972.

LIMA, E. L. G.; RIBEIRO, A.I.M. A Faculdade de Filosofia, Ciências e Letras de Presidente Prudente (1959-1976): a gênese da FCT. Jundiaí: Paço Editorial, 2013.

MOREIRA, J. C. C. Saberes em campo: a configuração do ensino escolar da Educação Física no Estado de São Paulo (1964-1985). 2013. 321 f. Tese (doutorado) - Universidade Estadual Paulista Júlio de Mesquita Filho, Faculdade de Ciências e Letras de Araraquara, 2013.

OLIVEIRA, E.T. Memórias docentes sobre o início da Unesp em Presidente Prudente: busca por meio de imagens (1975 - 1980). 2014. 204 f. Dissertação (Mestrado em Educação) - Faculdade de Ciências e Tecnologia, Universidade Estadual Paulista "Júlio de Mesquita Filho", Presidente Prudente.

PRESIDENTE PRUDENTE. Lei Municipal no 2.120, de 20 de Agosto de 1980, alteração da denominação da autarquia Escola Municipal Superior de Educação Física para Instituto Municipal de Ensino Superior de Presidente Prudente. Disponível em:< 
http://www.presidenteprudente.sp.gov.br/site/Documento.do?cod=32555 >. Acesso em: 08 ago. 2017.

PRESIDENTE PRUDENTE. Decreto Municipal no 4.341, de 10 de fevereiro de 1981. Fica a autarquia municipal de Presidente Prudente responsável pela administração e manutenção do Estádio de Atletismo Paulo Egydio Martins. Disponível em:< http://www.presidenteprudente.sp.gov.br/site/Documento.do?cod=31662>. Acesso em: 08 ago. 2017.

PRESIDENTE PRUDENTE. Lei Municipal n.o 2.625, de 08 de maio de 1988, que extinguiu o Instituto Municipal de Ensino Superior de Presidente Prudente. Disponível em: $<$ http://www.buscaoficial.com/c/diario/cC1JbgfKt/>. Acesso em: 08 ago. 2017.

SÃO PAULO. Conselho Estadual de Educação. Parecer CEE no 2.994/1973. Reconhecimento do curso de graduação em Educação Física e Técnico Desportivo. Disponível em:< http://iage.fclar.unesp.br/ceesp/textos/1973/par 299473 pro 188673 s Maiara c flavia flavi a.pdf>. Acesso em: 08 ago. 2017.

SÃO PAULO. Conselho Estadual de Educação. Processo CEE no 559/2001. Reautuado em 16 de outubro de 2002 (O documento tem característica intertextual por mencionar a Portaria Ministerial no 59, de 20 de maio de 1988; já que não foi possível obter este registro). Disponível em: $<$ https://iage.fclar.unesp.br/ceesp/textos/2002/559-2001.doc >. Acesso em: 08 ago. 2017. SEVERINO, A. J. Metodologia do Trabalho Científico. São Paulo: Cortez, 2007.

STAFORD, A. A. S. et. al. Autarquias e demais entidades da administração indireta. Âmbito Jurídico, Rio Grande, XI, n. 59, nov. 2008. Disponível em: < http://www.ambitojuridico.com.br/site/index.php?artigo_id=5299\&_link=revista_artigos_leitura >. Acesso em: 08 ago. 2017. 